\title{
Swimming exercise and race performance in Thoroughbred racehorses
}

\author{
Mariet Klomp', Carolien C. B. M. Munsters ${ }^{1,2}$, Marianne M. Sloet van Oldruitenborgh-Oosterbaan ${ }^{7}$ \\ 1 Department of Equine Sciences, Faculty of Veterinary Medicine, Utrecht University, Utrecht, the Netherlands \\ 2 Moxie Sport Analysis \& Coaching, Uden, the Netherlands
}

\begin{abstract}
Swimming has become an accepted part of the training programme of race horses. The purpose of this study was to establish whether it was possible to perform a standardized swimming test in race horses and to evaluate whether exercise variables calculated from this test were related to race track performance. Fifty-two Thoroughbred racehorses (4.6 \pm 1.4 years; 50 geldings and 2 stallions) participating in races at the Hong Kong Jockey Club (HKJC), were used in the study. All horses underwent a swimming test consisting of two laps of an oval shaped swimming pool ( $1 \mathrm{lap}= \pm 60 \mathrm{~m})$. During the swimming test, heart rate (HR; beats/min) and speed $(\mathrm{V} ; \mathrm{m} / \mathrm{s})$ of the horses were monitored. Additionally, 10 of the 52 horses were tested a second time (after 1-21 days), to evaluate the repeatability of the swimming test and after the second swimming test plasma lactate concentration (LA; mmol/L) was estimated. 'Performance Rating' of horses was defined by the rating score determined by the HKJC, based upon race performance. For a second performance parameter ('Performance Category'), horses were divided into 'good performers' (placed in 1 to 5 rank at competition in the period between 1 month before to 1 month after the swimming test) and 'average performers' (placed at lower rankings). Mean HR during the first swimming test was $178 \pm 14 \mathrm{bpm}$, the mean $V$ was $1.06 \pm 0.10 \mathrm{~m} / \mathrm{s}$. There was a significant correlation between $H R$ and $V(r=0.720, P<0.001, n=52), b u t$ HR was not repeatable between tests $(r=0.390, P=0.265, n=10)$. No significant correlation was found between racing performance and heart rate, speed or plasma lactate concentration. Under the existing circumstances it was not possible to perform a repeatable standardised swimming test. The results of the swimming test were not a useful predictor of either Performance Rating or Performance Category. Some horses reached high heart rates during the swimming test and one horse also showed a plasma lactate concentration above anaerobic threshold, indicating that the exercise of swimming may not be always as mild as some trainers think.
\end{abstract}

Keywords: swimming test / performance / heart rate / speed / Thoroughbred racehorse / exercise physiology

\section{Schwimmtraining und Rennleistung beim Vollblut-Rennpferd}

Schwimmen hat sich zur anerkannten Trainingsmethode für Rennpferde entwickelt. Ziel dieser Studie was es festzustellen, ob es beim Rennpferd möglich ist, einen standardisierten Schwimmtest durchzuführen und zu prüfen, ob die Leistungsvariablen aus diesem Test zu der Rennleistung auf der Bahn in Beziehung gesetzt werden können. 52 Rennpferde (4.6 1.4 Jahre; 50 Wallache und 2 Hengste), die im Hongkong Jockey Club (HKJC) im Rennen standen, nahmen an der Studie teil. Alle Pferde wurden einem Schwimmtest unterzogen, der in zwei Runden in einem ovalen Pool ( 1 Runde $=60 \mathrm{~m}$ ) bestand. Während des Tests wurden Herzfrequenz (HR, bpm) und Geschwindigkeit (V, m/s) der Pferde aufgezeichnet. Zusätzlich wurden 10 der 52 Pferde nach 1-21 Tagen ein zweites Mal getestet, um die Wiederholbarkeit des Test zu überprüfen. Nach diesem zweiten Test wurd auch die Plasmalaktatkonzentration (LA, mmol/L) gemessen. Die Leistungsbeurteilung der Pferde wurde anhand des Scores definiert, der vom HKJC basierend auf der Rennleistung festgelegt worden war. Für einen zweiten Leistungsparameter (Leistungskategorie) wurden die Pferde in "gute Leistungsbringer" (1.-5. Platzierung im Zeitraum von 1 Monat vor bis 1 Monat nach dem Schwimmtest) und "durchschnittliche Leistungsbringer" (nachrangige Platzierungen) eingeteilt. Die mittlere Herzfrequenz während des Schwimmtests war $178 \pm 14$ bpm, die mittlere Geschwindigkeit $V$ war 1,06 $\pm 0,10 \mathrm{~m} / \mathrm{s}$. Zwischen HR und $V$ bestand eine signifikante Korrelation $(r=0,720, P<0,001, n=52)$, jedoch war HR zwischen den verschiedenen Test nicht wiederholbar $(r=0,390$, $P=0,265, n=10)$. Zwischen Rennleistung, HR, V und Plasmalaktatkonzentration bestand keine signifikante Korrelation. Unter den gegebenen Umständen war es nicht möglich, einen wiederholbaren standardisierten Schwimmtest durchzuführen. Die Testergebnisse ließen keine brauchbare Vorhersage weder für die Leistungseinschätzung noch für die Leistungskategorie zu. Einige Pferde erreichten während des Tests hohe Herzfrequenzen und ein Pferd zeigte zudem über der anaeroben Schwelle liegende Plasmalaktatkonzentration, was darauf hinweist, dass Schwimmtraining nicht immer so "sanft" ist, wie manche Trainer meinen.

Schlüsselwörter: Schwimmtest / Leistung / Herzfrequenz / Geschwindigkeit / Vollblutrennpferd / Leistungsphysiologie

Correspondence: Prof. Dr. Marianne Sloet, Department of Equine Sciences, Faculty of Veterinary Medicine, Utrecht University, Utrecht, Yalelaan 1 12, 3584 CM Utrecht, The Netherlands, Email: m.sloet@uu.nl

Citation: Klomp M., Munsters C. C. B. M', Sloet van Oldruitenborgh-Oosterbaan M. M. (2014) Swimming exercise and race performance in Thoroughbred racehorses. Pferdeheilkunde 30, 403-406

\section{Introduction}

In some racing stables, swimming has become an accepted component of the training programme of race horses. Swimming is considered to be a relatively safe exercise for a horse because it is thought to provide sufficient workload with only limited strain on the limbs (Thomas et al. 1980, Misumi et al. 1994a).
Although no specific research on the possible correlation between swimming and track performance of race horses has been reported, the same linear increase in HR with increasing workload for horses running on the track has been found for swimming horses (Thomas et al. 1980). More experienced horses have been shown to have a lower HR after swimming than those that were less experienced in their training regimen 
(Garcia and Beech 1986). In swimming horses a positive correlation between maximum heart rate and swimming speed has also been shown, but there was no significant difference between the start and the end of a training period (Misumi et al. 1994b). This may be due to the fact that the horses in this study were not sufficiently accustomed to swimming and stress may have influenced the HR of horses during swimming tests (Misumi et al. 1994b).

During the racing season, the results of individual racehorses are closely monitored by the trainer. For horses that get regular swimming exercise and are accustomed to it, the measurement of exercise variables during swimming would be useful as a predictor of racing performance. The aim of the present study was to investigate whether heart rate and speed obtained during a standardized swimming test in racehorses that get regular swimming exercise, could be used to evaluate or predict on-track performance.

\section{Materials and methods}

\section{Horses}

In this study 52 Thoroughbred racehorses (mean age $4.7 \pm 1.4$ years, 50 geldings and 2 colts) were used. All horses were housed in individual stalls in eight different trainer departments at the Hong Kong Jockey Club (HKJC), and their housing, feeding and training was managed by their trainers (on average seven horses per trainer). All horses were trained six days a week in the swimming pool and on the track according to the training regimen of the trainer, and the seventh day was a rest day.

\section{Set up}

All 52 horses were tested in a standardized swimming test. Ten out of the 52 horses were tested twice to assess the repeatability of the results, with an interval of 1-21 days between test, depending on availability of the horse between the two swimming tests (test- 1 and test-2). In these 10 horses a jugular blood sample was taken after the test to determine plasma lactate concentration after swimming.

The swimming pool at the HKJC is an oval shaped pool with 22 meter straights and separate entrance and exit (Figures 1 and 2). The water in the pool was $2.6 \mathrm{~m}$ deep; horses therefore have no contact with the ground while swimming. During swimming the horses were guided by their own handler, along the outer edge of the pool. The water in the pool was not heated and the mean outside temperature was around $25^{\circ} \mathrm{C}$ during the whole experimental period.

\section{Swimming test protocol and blood sampling}

All 52 horses were tested using the same protocol. The heart rate monitoring equipment was fitted in the stable and the horse was hand-walked to the swimming pool. The test consisted of two laps of the pool. In the pool horses could take the inside or the outside of each corner, so to standardise distance versus HR only the 22 meter long straights of the pool were used to calculate mean HR and mean V. The first straight was not used in the data collection to allow the horses to adjust to the exercise. The data collected during swimming included the mean HR and $V$ for the second, third and fourth straight of the pool. In a subgroup of ten horses, a single heparinised blood sample was taken 1 minute after completing the swimming test and this was cooled immediately. Plasma lactate concentration was measured using a portable instrument (Lactate Pro ${ }^{\mathrm{TM}}$ )within 15 minutes after collection. The device has been shown to be accurate in equine blood assay (Sloet et al. 2008).

\section{Heart rate measurements}

The heart rate (HR) during swimming was measured using a HR monitor (Polar RS400, Polar Electro Oy, Kempele, Finland) with two plastic transmitters containing the electrodes. The two electrodes were placed on wet skin under the girth behind the left elbow and behind the left withers. The electrodes were held in place by an elastic strap and a small racing breastplate. HR monitors continuously recorded heart rate ( $H R$; beats/min) each second during the swimming test. The time was recorded for each straight using a stopwatch and the mean $H R$ and mean $V(m / s)$ were then calculated.

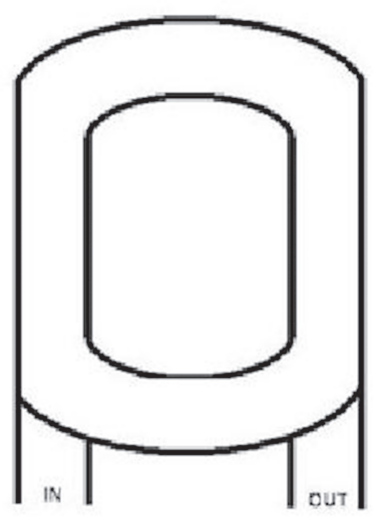

Fig. 1 Schematic representation of the swimming pool for horses at the Hong Kong Jockey Club: The pool is oval shaped with a separate entrance and exit; horses are guided in and out by a steep ramp which is covered with rubber tiles; in the middle of the pool is an island, so horses are forced to swim the full oval.

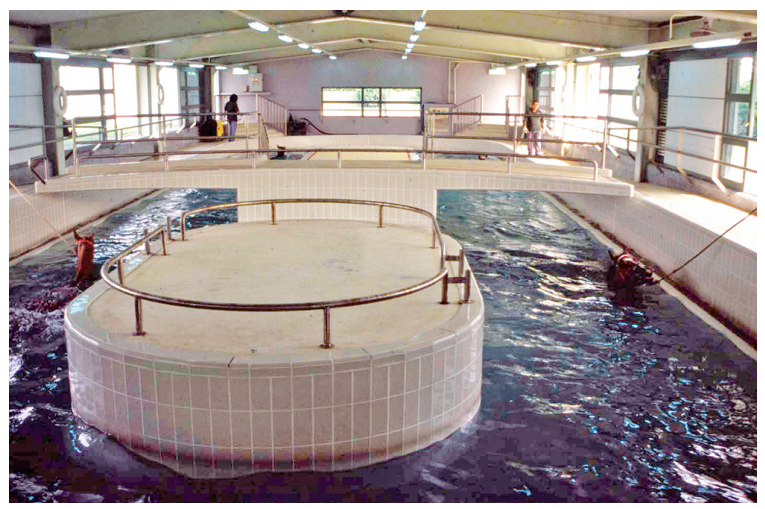

Fig. 2 Swimming pool for horses at the Hock Kong Jockey Club; horses always swim the full oval (the short-cut in the middle was not used). 


\section{Evaluation of racing performance}

'Performance Rating' around the swim date was obtained for each horse using the HKJC rating. This is a cumulative rating which is based on the outcome of all race competitions during the racing career up to the swim date for each horse. In addition, horses were classified as 'good performers' if they were placed in the top 5 in a race or as 'average performers' if they finished lower than fifth place (Couroucé et al. 1997). Races in the period from 1 month prior to 1 month after swim date were evaluated to determine this 'Performance Category'.

\section{Data analysis}

Data from all horses were used to calculate the correlation between HR and speed, using a Pearsons product-moment correlation. For the relationship between HR, speed, rating and performance a linear model was used, residues were checked for normality with $Q Q$-plots. In the subgroup of ten horses the correlations between HR and speed, HR and LA and speed and LA were calculated using a Pearson's productmoment correlation. The relationships between $L A$, rating and performance were also analysed using a linear model and residues were checked for normality with $Q Q$-plots.

\section{Results}

All horses

$H R$ values of all horses in the first test ranged from 130 to $202 \mathrm{bpm}$ with an average of $178 \pm 14$ beats/min. Swimming speed ranged from 0.79 to $1.28 \mathrm{~m} / \mathrm{s}$ with an average of $1.06 \pm 0.09 \mathrm{~m} / \mathrm{s}$. The heart rate of the horses was significantly correlated with swimming speed $(r=0.720, P<0.001)$ (Figure 3). Performance Rating and Performance Category were not correlated to HR or swimming speed.

\section{Horses tested twice}

In this subgroup of horses $(n=10), H R$ values ranged in test1 from 163 to 193 beats per minute with an average of $176 \pm 10$ beats/min and in test- 2 from 149 to 209 beats/min with an average of $179 \pm 16$ beats/min (Figure 4). HR was not significantly correlated between test- 1 and test- 2 $(r=0.390, p=0.265)$.

\section{horses in a swimming test}

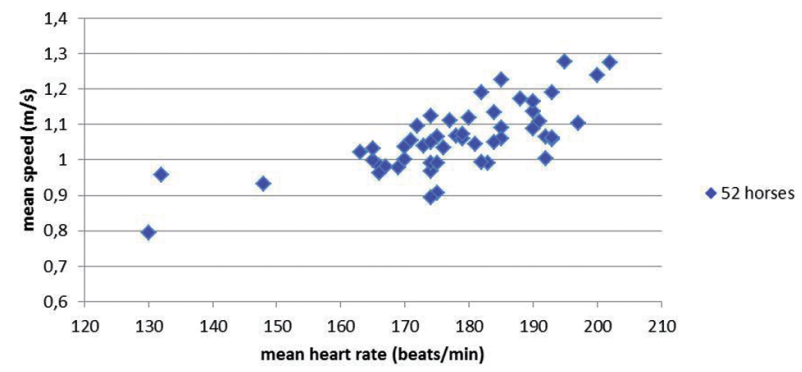

Fig. 3 Correlation between mean heart rate and mean swimming speed in 52 horses performing a swimming test.
Mean swimming speed of test- 1 was $1.05 \pm 0.073 \mathrm{~m} / \mathrm{s}$ (range 0.98 to $1.23 \mathrm{~m} / \mathrm{s}$ ) and of test $-21.06 \pm 0.08 \mathrm{~m} / \mathrm{s}$ (range $0.96-1.20 \mathrm{~m} / \mathrm{s}$ ). Speed was significantly correlated between test- 1 and test-2 ( $r=0.670 ; p=0.034)$.

The average plasma lactate concentration in the subgroup was $2.3 \pm 1.6 \mathrm{mmol} / \mathrm{L}$. No significant correlation was found between mean heart rate or mean speed and plasma lactate concentration LA. Performance Rating and Performance Category showed no correlation with the plasma lactate concentration. A single horse had a higher than average plasma lactate concentration of $6.6 \mathrm{mmol} / \mathrm{L}$.

\section{Discussion}

The heart rate values of 130-202 bpm obtained during the swimming tests were closely comparable with the 130-210 bpm previously reported (Hobo et al. 1998, Misumi et al.1994a and b, Thomas et al. 1980). Maximum heart rate during the swimming test in the present study (202 bpm) was lower than the average maximum heart rate of $223 \mathrm{bpm}$ in Thoroughbred horses during a race (Krzywanek et al. 1970). In the present study, it was found that heart rate during the swimming test was not a good predictor of performance on the race track. Other previous studies on swimming test and race performance were also unable to establish a correlation (Misumi et al. 1994a, b). Therefore, it seems that there is no relationship between the heart rate of horses during a swimming test and race track performance.

In the present study heart rate of horses was not repeatable between two swimming tests. However, Garcia et al. (1986) found that heart rate of horses between two repeated swimming tests were comparable $(117 \pm 8 \mathrm{bpm}$ and $110 \pm 5$ $\mathrm{bpm})$. The reason for the lack of repeatability of heart rate in the present study is not clear, but it may be partly explained by the variable period between the repetition of the two tests. Other possible explanations may be that the intensity of the swimming test used in the study of Garcia et al. (1986) was lower than the average intensity during the swimming test in the present study (130-202 bpm) and therefore the heart

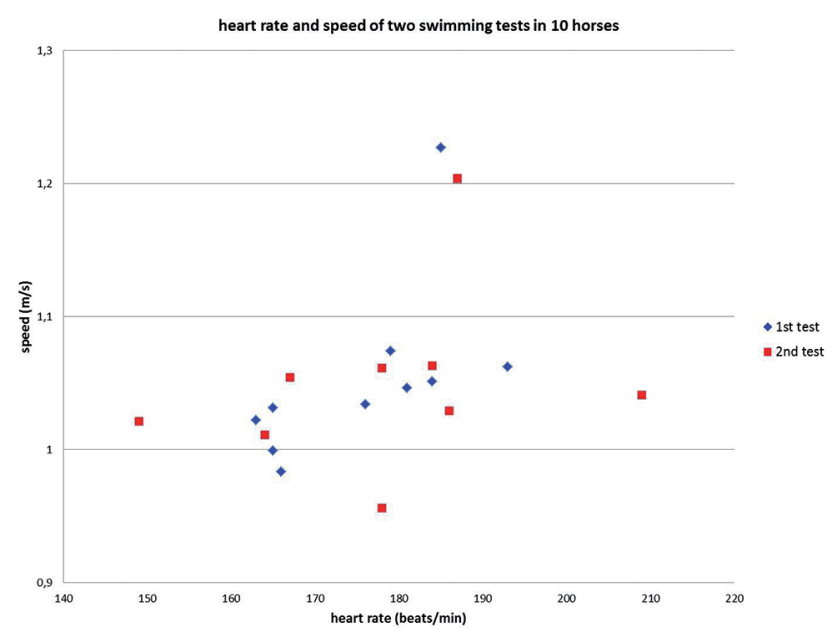

Fig. 4 Correlation between mean heart rate and mean speed in the subgroup of 10 horses that were tested twice in a swimming pool. 
rate variations smaller. Finally, the sample size might have been too small in the present study.

The swimming speed of horses was significantly correlated between the two swimming tests. Each horse appeared to swim at its own 'preferred' swimming speed, and from the authors experience it proved very difficult to change a horses' speed during swimming. There was also no relationship between swimming speed and Performance Rating or Performance Category.

The average plasma lactate concentration $(2.3 \pm 1.6 \mathrm{mmol} / \mathrm{L})$ obtained in this study is comparable with data found in earlier swimming studies (Hobo et al. 1998, Gatta et al. 1999). In the present study one horse had a higher plasma lactate concentration after the swimming test $(6.6 \mathrm{mmol} / \mathrm{L})$; this suggests that during swimming exercise the anaerobic contribution to the energy demands of this horse was quite significant. Therefore, it might be important for horse trainers to appreciate that swimming should not be considered as a mild exercise for every individual horse - a conclusion that has also been suggested by other authors (Thomas et al. 1980).

A correlation between plasma lactate concentration and racing performance of Thoroughbred race horses was demonstrated during a standardised treadmill test (Evans et al. 1993), but in the present study, LA during the swimming test was not correlated to Performance Rating or Performance Category. Misumi (1994a,b,c) found no differences in LA between a swimming test at the beginning of a training period and after four months of training. Therefore, it also seems likely that there is no correlation between plasma lactate concentrations during a swimming test and the performance of race horses.

\section{Conclusions}

In the present study it was not possibe to standardise a swimming test in race horses. Mean heart rate, mean speed and plasma lactate concentrations during a swimming test were not useful indices of the racing performance. In some horses swimming exercise may not be such 'mild' exercise as is sometimes suggested.

\section{Acknowledgements}

The authors thank dr. Greg $\bigcirc$. Sommerville for the opportunity to perform this study at the Hong Kong Jockey club and for all his advice and help during the study. We are also very grateful to all trainers and owners of the horses that participated in the study. We thank dr. Jan van den Broek for statistical evaluation.

\section{References}

Couroucé A., Chatard J. C., Auvinet B. (1997). Estimation of performance potential of Standardbred trotters from blood lactate concentrations measured in field. Equine Vet. J. 29, 365-369

Evans D. L., Harris R. C., Snow D. H. (1993) Correlation of racing performance with blood lactate and heart rate after exercise in Thoroughbred horses. Equine Vet. J. 25, 441-445

Garcia M. C., Beech J. (1986) Endocrinologic, hematologic, and heart rate changes in swimming horses. Am. J. Vet. Res. 47, $2004-$ 2006

Gatta D., Casini L., Magni L., Colombani B. (1999) The workload during swimming training in Thoroughbreds: comparison with two different training sessions on the track. Annali della Facolta di Medicina Veterinaria di Pisa 52, 179-187

Hobo S., Yoshida K., Yoshihara T. (1998) Characteristics of respiratory function during swimming exercise in Thoroughbreds. J. Vet. Med. Sci. 60, 687-689

Krzywanek H., Wittke G., Bayer A., Borman P. (1970) The heart rates of Thoroughbred horses during a race. Equine Vet. J. 2, 115-1 17

Misumi K., Sakamoto H., Shimizu R. (1994a) The validity of swimming training for two-year-old Thoroughbreds. J. Vet. Med. Sci. 56, 217-222

Misumi K., Sakamoto H., Shimizu R. (1994b) Changes in blood lactate and heart rate in Thoroughbred horses during swimming and running according to their stage of training. Vet. Rec. 135, 226228

Misumi K., Hirakawa A., Sakamoto H., Shimizu R. (1994c). Principal component analysis, using the measurements during running and swimming test in Thoroughbred horses. J. Vet. Med. Sci. 56, 1075-1080

Sloet van Oldruitenborgh-Oosterbaan M. M., van den Broek E. T. W., Spierenburg A. J. (2008) Evaluation of the usefulness of the portable device Lactate Pro for measurement of lactate concentrations in equine whole blood. Vet. Diagn. Invest. 20, 83-85

Thomas D. P., Fregin G. F., Gerber N. H., Ailes N. B. (1980). Cardiorespiratory adjustments to tethered-swimming in the horse. Pflügers Archiv: Europ. J. Physiol. 385, 65-70 